\title{
Adolescents' educational level and computer use: An exploratory study of the relationship between adolescents' current educational level and the use of computer applications and computer attitudes
}

\author{
KLAAS GUTSCHOVEN
}

\section{Abstract}

This study focuses on two research questions. First, I will investigate whether or not the current educational level of adolescents is a meaningful concept in multimedia research. Second, the relevance of current educational level is compared to the concept of parental education that has been used in (multi)media research so far.

The research questions were addressed by means of a quantitative study of 232 secondary school students in Flanders about their multimedia use and attitudes towards multimedia. The results suggest that when the relationship between parental education and multimedia uselattitudes is controlled for adolescents' current educational level, it becomes insignificant. Adolescents' current educational level, on the other hand, remained significant throughout the whole of the analysis, even when controlled for parental education. Based on these results I conclude that there is considerable evidence indicating that, first of all, current educational level is indeed a meaningful concept in multimedia research and, secondly, that when multimedia research is focused on adolescent behavior it is advisable to include current educational level as a measure of social class in the analysis.

Keywords: adolescents, computer use, education, attitude, Flanders, multimedia

There is little to no previous research on the relationship between adolescents' current educational level and computer use. Instead, previous research efforts have mainly focused on parental socio-economic variables, such as educational level or profession as an indication of a child's socioeconomic status (Brown, Childers, and Walsh, 1990; Muijs, 1997; Johnsson-Smaragdi, d'Haenens, Krotz, and Hasebrink, 1998; Pasquier, Busi, d'Haenens, and Sjöberg, 1998). 
The importance of parental education has been stressed by many researchers. Brown et al. (1998), for instance, used parental education, together with maternal employment and father's presence, as a measure for family environment assuming "that the measure of parent education is related to both family income and cultural values". The results showed a significant relationship between parental education and the possession of multiple media technologies. According to the authors, the latter result is probably the consequence of a greater family income acquired by higher educated parents. Roe (2000) tested the relationship between parent related socio-economic variables and children's television use. $\mathrm{He}$ found that both father's occupational and mother's educational status were significantly related to the number of TV-sets in the home. On average the groups with more television sets at home were those with mothers in the lowest educational status groups. On the other hand, father's occupational status was positively correlated with the dependent variable. When these results were controlled for gender, the relationship of mother's educational status became significant only for girls (Roe, 2000: 3-15). Van Rompaey (2002) also found that mother's mean educational status significantly differed in the three family types she defined in terms of multimedia possession. In traditional families mothers had a lower educational level than in intermediate and multimedia families. Roe (1998, 2000) as well as Rosengren and Windahl (1989: 125) point to the fact that "media use has been found to be differentially structured in different social classes" (Roe, 2000: 6). Controlling for gender and social class, Rosengren and Windahl (1989) measured the use of eight different media in three waves. They found significant structures in media use as well as differences in the structures and the degree of structuring itself. They found the media use of girls to be at least twice as structured as that of boys. Rosengren and Windahl (1989) concluded that "the media culture of youth is structurally differentiated along age, gender and social class".

In regard to children, however, concepts of social class are hard to measure. Children do not have an income of their own and in primary school a distinction between high and low levels of education is often not possible. As noted before, the solution to this problem has often been found in directly transferring parental socio-economic characteristics to their children. Father's and mother's educational status and/or professional status then serve as indicators for measuring social class in children.

On the other hand, the measurement of social class through parental characteristics could be problematic in the case of adolescents. In fact, Roe (2000) underlines this and Rosengren and Windahl (1989) stress the need to differentiate between the concepts of class of origin and class 
of destination. The problem in respect to adolescent research arises in that the authors state that the relative importance and relationship between class of origin and class of destination does not remain the same throughout the different stages of life. Rosengren and Windahl (1989) especially identify the period of adolescence to be the critical life stage of transition from class of origin towards class of destination.

For example, while the social class status of adolescents is largely defined by that of their parents, that of adults tends more to be based on educational and occupational self-attainment (class of destination). For adolescents the situation is more equivocal since they find themselves in a transitional context in which, as they get older, the significance of their class of origin steadily diminishes and their eventual situation in the status hierarchy becomes increasingly discernible (Roe, 2000: 4).

Rosengren and Windahl's (1989) assumption about the respectively decreasing and increasing values of class of origin and class of destination during the process of children becoming adolescents has provided the basic elements of this study's research questions. The main question of this study then is whether or not differences in adolescents' current educational level should be taken into account when investigating the relationship between social class (in terms of class of destination) and (multi)media use in adolescents. After all, the more a child becomes an adolescent, the more class of destination will gain importance as one of the most central components of the measurement of social class instead of class of origin. Whereas earlier research has mainly focused on class of origin as the main component of a child's social class, one could argue that with respect to adolescents the focus should be shifted towards class of destination, or as Roe (1992) calls it 'anticipated social status'. Research by Roe (1994) indicated that current educational level could be a good measure for class of destination. He found that there is a relationship between school achievement and later educational status which is stronger than the relationship of the latter concept with the educational level of the mother.

However, before judging the relevance of these assumptions and findings with respect to multimedia research, one should first be able to assess whether or not current educational level is at all a meaningful concept in this particular research domain. This research was designed to assess and compare the relevance of the concepts of current educational level and parental educational level with respect to multimedia research by means of data about secondary school adolescents' computer use and computer attitudes. 


\section{Research design}

The data for this study were gathered in the Flemish community of Belgium. Flanders' educational system is especially suitable for this research since it makes it possible to draw the necessary distinction between different levels of secondary school education. Three levels of education are firmly distinct: ASO, TSO and BSO. These educational levels differ from one another in that they all have a different orientation towards theory, vocational training, or a mixture of both. Generally, in ASO the main emphasis is on theoretical courses and subjects such as science, mathematics, economics and languages. Little or no attention is paid to practical experience. The main aim of this kind of secondary education is to prepare adolescents for higher education at an academic or college level. TSO, on the other hand, is more practical and less theoretical than ASO and as such is positioned between ASO and BSO. The latter is almost completely practical with just a minimal orientation towards theoretical courses such as the ones referred to above.

Thus, whereas ASO adolescents are prepared for academic education, at the TSO and especially the BSO level, pupils are trained for specific professions such as construction work, hairdressing, woodwork, etc. For TSO graduates, however, advanced study, although mostly non-academic, in areas such as teaching, nursing, secretary work, accounting is also an option. It seems plausible then to state that the highest education is offered in ASO schools, intermediate education in TSO and lower education in BSO. In the remainder of this article I will, therefore, refer to low, middle and high level education instead of the technical terminology of BSO, TSO and ASO.

To illustrate this rank order I would like to refer to figures about flow into and success rates in university education of students from each of these educational levels. Since higher education is generally not an option for lower education students, data for this particular group have never been gathered. For high and middle education students, however, Stinissen (1987) found that flow through to university and success rates are much higher for high than for middle level students. In this study $43 \%$ of all high education students went to university and $52 \%$ of those succeeded in their efforts. In respect to middle level students these numbers are much lower with only $4 \%$ going to university and only $29 \%$ achieving success. None of the low education students in the study started higher education on an academic level. Since these figures indicate that educational level in secondary school is a strong correlate of flow through and success rates in higher education and, therefore, professional opportunities, current educational level is assumed to be a valid measure of 'class of destination'. 
The situation in Flanders with three firmly distinct levels of education makes it possible for researchers to focus on the relationship between class of destination, measured through adolescents' own level of educational level, and (multi)media use. As noted before, this article specifically aims to investigate and judge the relevance of the relationship between adolescents' current educational level and computer use as well as computer attitudes. The main research questions therefore are:

R1: To what extent is an adolescent's current educational level related to the time $\mathrm{s} / \mathrm{he}$ spends using different computer applications?

R2: In what way is an adolescent's current educational level related to his/her attitudes towards the computer?

R3: How does current educational level relate to parental education and what is its significance within the measurement of social class in adolescents?

Furthermore, the findings of Rosengren and Windahl (1989) about media being structured along the lines of gender (cf. supra) lead us to examine if and how gender influences the relationship between current educational status and computer use/attitudes.

R4: Does a significant interaction effect of gender and educational level on the use of different computer applications exist?

R5: Does a significant interaction effect of gender and educational level on computer attitudes exist?

\section{Method}

\section{Subjects}

Three schools were randomly selected from a list of secondary schools in Flanders. Since my study focused on between group comparison instead of on conclusions with respect to the general population, randomness of the sample was considered to be more important than representativeness.

In each of the selected schools two classes in the third as well as in the fourth grade were selected (twelve schools in total). For practical reasons only classes from one educational level were selected in each school. It would be wrong, however, to assume that therefore school as such was indicative of the respondents' educational level. After all, each of the selected schools also offered the two other educational levels. As for the computer facilities in the different schools, one can expect that no significant differences between the three schools existed. In Flanders, thorough computer education is a part of all curricula in each educa- 
tional level. Schools are therefore obliged to offer decent computer facilities to all of their students. Even if these differences would have occurred, one can assume that their impact on this study would have been negligible since my research questions mainly focused on computer use at home.

None of the students that were selected refused or was unable to fill out the questionnaire. All respondents were, at the time, between 15 and 18 years of age $(\mathrm{M}=15,81 ; \mathrm{SD}=.89)$. As a result of the sampling method there was an approximately equal amount of boys and girls in every grade and in each of the three different educational levels that were described earlier (high, middle and low). The only exception was in the lower education level, where slightly more girls than boys filled out the questionnaire. It was also in this educational group that the total amount of respondents was slightly lower than in both high and middle education (table 1).

Table 1. Gender * educational level.

\begin{tabular}{lllll}
\hline & \multicolumn{3}{l}{ Educational Level } & Total \\
\cline { 2 - 4 } & BSO & TSO & ASO & \\
\hline Gender & 35 & 40 & 40 & 115 \\
Male & 37 & 40 & 40 & 117 \\
Female & 72 & 80 & 80 & 232 \\
Total & & & & \\
\hline
\end{tabular}

\section{Concepts and measures}

A total of twelve dependent and four independent variables were measured. Each of the independent variables (gender, current educational level, educational level of the father and educational level of the mother) was measured by single questions. Educational level was measured through an open ended question asking the respondent for his/her specific type of studies. During the coding process these answers were classified into the corresponding educational level (high, middle or low). Both father's and mother's educational level were measured by means of closed survey questions. For both their father and their mother, respondents were asked to indicate the highest degree ever attained on a four point scale: (1) primary school, (2) secondary school, (3) higher non-academic, (4) academic degree.

Then, the use of five different computer applications was measured: internet use, e-mail and chat frequency, computer game playing and computer use 'for functional purposes'. The operationalization of the latter 
concept was inspired by Ho and Lee (2001) who measured computer use by asking the students to indicate how often they used the computer for completing homework assignments. This seemed to be an accurate operationalization for two reasons. First of all, homework is a very important and time consuming occupation for secondary school students. Second, the role of the computer as an instrument for helping students with their homework has become increasingly important (Ho and Lee, 2001; Subrahmanyam, Kraut, and Greenfield, 2000).

The usage frequency of each of these five computer applications was measured by asking the respondents how often they engaged in that particular behavior. A six point scale was used with items ranging from (0) 'never' to (6) 'several times a day'. In respect to 'functional computer use' the question specifically stated 'use at home' since functional computer use could also occur at school. Computer use at school was excluded from the analysis since it was expected to correlate with educational level and as such interfere with the main focus of this study. Each of these questions was then followed by an eleven points Likert scale $(0-10)$ on which respondents were asked to indicate how much they liked using this specific application.

Computer attitudes were measured using the Computer Attitudes Scale of Loyd and Loyd (1985). A historical overview of the development and evolution of the CAS has been given by Nash and Moroz (1997). The first version of the CAS by Loyd and Gressard (1984) consisted of 3 different attitudes: 1) 'computer anxiety'; 2) 'computer liking'; 3) 'computer confidence'. One year later Loyd and Loyd (1985) completed the CAS with a fourth factor, 'computer usefulness'. Additional evidence for the reliability and factorial validity of the CAS by Loyd and Loyd (1985) can be found in Green and Swearing (1994).

\section{Statistics}

To test whether or not a significant between group variation in application use or computer attitudes for the different educational groups exists, a one way Analysis Of Variance (ANOVA) for educational level was run on each of the dependent variables. When the ANOVA results were significant a post-hoc Tukey test was conducted in order to be able to specify any significant between group differences. The main effect of gender was measured by means of a t-test for independent samples.

The interaction effect of gender and educational level on the dependent variables was measured using a General Linear Model (GLM). In the GLM main effects of educational level of the mother and the father were also included in order to be able to judge the relative importance of both the current and the parental educational level concepts by means 
of the squared Eta's. Since correlations between each of the three educational measures did not exceed a significant level of .80, no problems of multicollinearity were expected to interfere with the reliability of the squared Eta comparison (Field, 2000: 131-132).

The use of a GLM also provided the possibility to test whether or not the main effects of gender and educational level found in the ANOVA and T-test would remain significant when controlling not only for each other but also for educational level of both the mother and the father. When the model as a whole was significant, and a significant interaction was found, ANOVAs were run once more. This time, however, the tests were conducted separately for boys and for girls so as to determine the exact influence of gender on the relationship between educational level and computer use/attitudes. Again post-hoc Tukey tests were used to determine the exact location of the between group variations that were suggested in the gendered ANOVAs.

\section{Results}

The relationship between parental education and current educational level

The analysis indicated that a significant relationship exists between educational level of the parents and a child's current educational level. A multiple regression model with current educational level as the dependent variable and educational level of the father and the mother as independent variables indeed proved that both independent factors were significant predictors of current educational level. As a whole, however, the model could only explain $22,5 \%$ of the variance in the dependent variable. Or, in other words, when both educational level of the father and of the mother are known, one can only predict current educational level in approximately one out of five cases.

In previous research the transition of children to a social class different to that of their parents has been referred to as 'social mobility' (Roe, 1994). In terms of Roe (1994) children with higher educated parents who do not attain this level of education themselves are referred to as 'higher education droppers'. Those having no parents with a higher education, but who succeed in attaining a college or university degree were called

Table 2. Multiple regression: Dependent variable educational level.

\begin{tabular}{lccc}
\hline & Beta & $\mathrm{t}$ & Sig. \\
\hline Father's level of education &, 256 & 3,301 &, 001 \\
Mother's level of education &, 312 & 4,033 &, 000 \\
\hline
\end{tabular}

$\left(\mathrm{F}=24,31 ; \mathrm{DF} 2 ; \mathrm{R}^{2}=.225\right)$ 
the 'higher educational climbers'. Those with higher educated parents who also attain this status themselves are the 'higher educated stationary'. Apparently, in this research, a significant percentage of droppers and climbers can be identified. It thus seems that parental education and current educational level are significant correlations but that the predictive power of parental education is rather small. Both variables thus measure different concepts.

\section{Computer applications}

A one-way ANOVA for the use of each of the five computer applications and their preference scales with current educational level revealed significant between group differences for the usage frequency of four of them (table 3). Only the amount of computer game playing did not significantly differ in the different educational groups. As for the liking of the computer applications, the ANOVA only revealed a significant relationship with respect to the linking of e-mail.

Of the actual differences between each of the three educational groups and the use of different computer applications the most obvious patterns revealed by the post-hoc Tukey tests were the ones for e-mail frequency and Internet use. The results (table 4) indicate that a positive linear relationship exists in that the mean score of middle education students on e-mail frequency is higher than that of students in low education, but lower than the score of their high education peers who use this particular application the most. In other words, the higher the education, the higher the e-mail frequency. The results found for Internet use and chat frequency are similar in that high education students also use these applications significantly more than their middle and low education peers.

Table 3. ANOVA Educational level * computer applications.

\begin{tabular}{lrrrrr}
\hline Computer applications & $\begin{array}{c}\text { Sum of } \\
\text { Squares }\end{array}$ & df & $\begin{array}{l}\text { Mean } \\
\text { Square }\end{array}$ & F & Sig. \\
\hline Frequency of video or computer games & 6,918 & 2 & 3,459 & 2,358 &, 097 \\
Preference for video and computer games & 20,849 & 2 & 10,424 & 1,290 &, 277 \\
Frequency of using the internet & 27,507 & 2 & 13,753 & 10,944 &, 000 \\
Preference for using the internet & 2,340 & 2 & 1,170 &, 205 &, 815 \\
Frequency of using e-mail & 91,659 & 2 & 45,830 & 27,376 &, 000 \\
Preference for using e-mail & 220,330 & 2 & 110,165 & 16,136 &, 000 \\
Frequency of using chat & 40,251 & 2 & 20,126 & 10,310 &, 000 \\
Preference for using chat & 37,072 & 2 & 18,536 & 2,185 &, 115 \\
Frequency of using the computer & 9,865 & 2 & 4,932 & 3,187 &, 043 \\
Preference for using the computer & 14,455 & 2 & 7,228 & 1,631 &, 198 \\
\hline
\end{tabular}


Table 4. Post-hoc Tukey test for computer applications * education.

\begin{tabular}{|c|c|c|c|c|c|}
\hline Dependent Variable & (I) EDUC & (J) EDUC & $\begin{array}{l}\text { Mean Differ- } \\
\text { ence }(I-J)\end{array}$ & $\begin{array}{l}\text { Std. } \\
\text { Error }\end{array}$ & Sig. \\
\hline $\begin{array}{l}\text { Frequency of using } \\
\text { the internet }\end{array}$ & $\begin{array}{l}\text { BSO } \\
\text { TSO }\end{array}$ & $\begin{array}{l}\text { TSO } \\
\text { ASO } \\
\text { ASO }\end{array}$ & $\begin{array}{l}-, 13 \\
-, 79 * * \\
-, 66 * *\end{array}$ & $\begin{array}{l}, 18 \\
18 \\
, 18\end{array}$ & $\begin{array}{l}, 753 \\
, 000 \\
, 001\end{array}$ \\
\hline $\begin{array}{l}\text { Frequency of using } \\
\text { e-mail }\end{array}$ & $\begin{array}{l}\text { BSO } \\
\text { TSO }\end{array}$ & $\begin{array}{l}\text { TSO } \\
\text { ASO } \\
\text { ASO }\end{array}$ & $\begin{array}{r}-, 7634^{* *} \\
-1,5694^{* *} \\
-, 8061^{* *}\end{array}$ & $\begin{array}{l}, 21 \\
, 21 \\
, 20\end{array}$ & $\begin{array}{l}, 001 \\
, 000 \\
, 000\end{array}$ \\
\hline $\begin{array}{l}\text { Preference for } \\
\text { using e-mail }\end{array}$ & $\begin{array}{l}\text { BSO } \\
\text { TSO }\end{array}$ & $\begin{array}{l}\text { TSO } \\
\text { ASO } \\
\text { ASO }\end{array}$ & $\begin{array}{c}-, 49 \\
-2,28 * * \\
-1,79 * *\end{array}$ & $\begin{array}{l}, 43 \\
43 \\
, 42\end{array}$ & $\begin{array}{l}485 \\
, 000 \\
, 000\end{array}$ \\
\hline $\begin{array}{l}\text { Frequency of } \\
\text { using chat }\end{array}$ & $\begin{array}{l}\text { BSO } \\
\text { TSO }\end{array}$ & $\begin{array}{l}\text { TSO } \\
\text { ASO } \\
\text { ASO }\end{array}$ & $\begin{array}{c}-4,2735 \mathrm{E}-03 \\
-, 8806^{* *} \\
-, 8763^{* *}\end{array}$ & $\begin{array}{l}, 23 \\
23 \\
, 23\end{array}$ & $\begin{array}{r}1,000 \\
, 000 \\
, 000\end{array}$ \\
\hline $\begin{array}{l}\text { Frequency of } \\
\text { using the computer }\end{array}$ & $\begin{array}{l}\text { BSO } \\
\text { TSO }\end{array}$ & $\begin{array}{l}\text { TSO } \\
\text { ASO } \\
\text { ASO }\end{array}$ & $\begin{array}{c}-, 4844^{*} \\
-9,7107 \mathrm{E}-02 \\
, 3873\end{array}$ & $\begin{array}{l}, 20 \\
, 20 \\
, 20\end{array}$ & $\begin{array}{l}, 048 \\
, 883 \\
, 126\end{array}$ \\
\hline
\end{tabular}

Contrary to e-mail use, however, no significant differences were found between the middle and low education groups. The same pattern of scores was also noted for the 11-point preference scale of e-mail. High education students like e-mail more than middle or low education students who do not differ significantly from one another. Finally, the relationship of functional computer use with educational level follows yet another pattern. Here, only the scores of the low and middle groups differ significantly. Apparently middle education students use the computer more for functional purposes than low education students. However, they do not use it more than students in high education who spend an equal amount of time behind the computer while using it as a functional instrument.

To test whether gender relates to the usage and preference scales of the different computer applications, an independent sample t-test with gender as a grouping variable was run (table 5). The test revealed significant gender differences for usage and liking of computer games as well as usage and liking of Internet and liking of computer use for functional purposes. No significant gender differences were found for e-mail and chat on both the usage and the preference scales.

In line with the findings of previous research (Johnssons-Smaragdi et al., 1998; Roe, 1998; Busch, 1995), the results suggest that boys not only like computer games better than girls do but that they also play 
Table 5. Independent samples $t$-test for computer applications $*$ gender.

\begin{tabular}{lllllllll}
\hline Computer applications & Gender & $\mathrm{N}$ & Mean & $\begin{array}{l}\text { Std. } \\
\text { Deviation }\end{array}$ & $\mathrm{t}$ & $\mathrm{df}$ & Sig. \\
\hline Frequency of video & male & 115 & 4,00 &, 93 & 9,864 & 229 &, 000 \\
or computer games & female & 116 & 2,67 & 1,11 & & & \\
Preference for video & male & 114 & 7,94 & 1,97 & 9,575 & 228 &, 000 \\
and computer games & female & 116 & 4,90 & 2,77 & & & \\
Frequency of using & male & 115 & 3,87 & 1,06 & 1,300 & 228 &, 036 \\
the internet & female & 115 & 3,67 & 1,27 & & & \\
Preference for using & male & 111 & 8,10 & 1,98 & 2,379 & 221 &, 001 \\
the internet & female & 112 & 7,35 & 2,68 & & & \\
Frequency of & male & 113 & 3,38 & 1,3851 &, 247 & 225 &, 200 \\
using e-mail & female & 114 & 3,34 & 1,4923 & & & \\
Preference for & male & 114 & 6,11 & 2,73 & $-1,057$ & 225 &, 457 \\
using e-mail & female & 113 & 6,50 & 2,83 & & & \\
Frequency of & male & 114 & 3,23 & 1,4713 &,- 158 & 228 &, 741 \\
using chat & female & 116 & 3,26 & 1,4408 & & & \\
Preference for & male & 113 & 6,99 & 3,03 &,- 754 & 223 &, 544 \\
using chat & female & 112 & 7,29 & 2,83 & & & \\
$\begin{array}{l}\text { Frequency of using } \\
\text { the computer }\end{array}$ & male & 110 & 3,31 & 1,2630 & 3,650 & 224 &, 069 \\
$\begin{array}{l}\text { Preference for using } \\
\text { the computer }\end{array}$ & female & 116 & 2,72 & 1,1838 & & & \\
\hline & male & 114 & 8,71 & 1,50 & 6,872 & 228 &, 000 \\
\hline
\end{tabular}

them more often. In a similar way, boys also like surfing the Internet better than girls and as was found with respect to computer games they also surf more often. Finally, boys also like the use of the computer for functional purposes better than girls.

\section{Computer attitudes}

The ANOVA for the between group comparison of the mean scores of the educational groups on the Computer Attitude Scale of Loyd and Loyd (1985) revealed significant between group differences on three of the four CAS factors. In fact, the ANOVA indicated that mean between group differences were to be expected on the computer anxiety, computer liking and computer usefulness scales. These findings were confirmed by the results of the post-hoc Tukey test (see table 6).

For the computer liking scale, the low and middle education groups do not differ significantly from one another, but the middle education students scored higher than the high education group. A similar but 
Table 6. Post-hoc Tukey test for computer attitudes * education.

\begin{tabular}{llllll}
\hline Dependent Variable & (I) EDUC & (J) EDUC & $\begin{array}{l}\text { Mean } \\
\text { Difference } \\
\text { (I-J) }\end{array}$ & $\begin{array}{l}\text { Std. } \\
\text { Error }\end{array}$ & Sig. \\
& & & $-9,09 \mathrm{E}-02$ &, 78 &, 992 \\
Computer Confidence & BSO & TSO & 1,10 &, 80 &, 359 \\
& & ASO & 1,19 &, 76 &, 258 \\
& TSO & ASO &,- 14 &, 73 &, 979 \\
Computer Liking & BSO & TSO & 1,48 &, 73 &, 106 \\
& & ASO & $1,62^{*}$ &, 71 &, 049 \\
& TSO & ASO &, 81 &, 63 &, 400 \\
Computer anxiety & BSO & TSO & $-1,11$ &, 63 &, 180 \\
& & ASO & $-1,92^{*}$ &, 61 &, 005 \\
& TSO & ASO & $-1,19$ &, 63 &, 142 \\
Computer Usefulness & BSO & TSO & $-1,49 *$ &, 64 &, 050 \\
& & ASO &,- 30 &, 62 &, 876 \\
\hline
\end{tabular}

reversed pattern of between group differences was found for the computer anxiety scale. On this scale, the scores of the high education group also differed significantly from those of the middle students. Compared to the computer preference scale, however, the relationship was now reversed, meaning that middle education students scored lower than high education students. Apparently, computer liking is higher in middle education than in high education but not in low education. On top of that, the scores of the low and high education groups were not found to be significantly different. Finally, the results of the computer usefulness scale indicated that there is a significant difference between the mean scores of the low and the high education students whereby high education students consider the computer to be more useful than students in low education.

Similar to the procedure that was described earlier with respect to computer use, a t-test for independent samples was run on the CAS using gender as grouping variable (table 7). For each of the four components of the CAS, the t-test revealed a significant difference in mean scores of boys versus girls. On average, boys scored higher on factors that express positive attitudes towards the computer. These are computer confidence, computer liking and computer usefulness. Girls, on the other hand, scored higher on the computer anxiety factor, the latter being in fact the only factor expressing a negative attitude toward computers. A plausible conclusion then seems to be that boys, in general, have a more positive attitude towards computers than girls. 
Table 7. T-test for independent samples for gender * computer attitudes.

\begin{tabular}{llrlllll}
\hline Computer attitudes & Gender & $\mathrm{N}$ & Mean & $\begin{array}{l}\text { Std. } \\
\text { Devia- } \\
\text { tion }\end{array}$ & t & df. & Sig. \\
\hline Computer Confidence & male & 108 & 28,47 & 4,00 & 6,928 & 194 &, 000 \\
& female & 88 & 24,51 & 3,96 & & & \\
Computer Liking & male & 110 & 23,61 & 4,00 & 6,451 & 217 &, 000 \\
& female & 109 & 20,08 & 4,09 & & & \\
Computer anxiety & male & 112 & 13,88 & 3,64 & $-4,968$ & 215 &, 000 \\
Computer Usefulness & female & 105 & 16,31 & 3,59 & & & \\
& male & 106 & 24,79 & 3,48 & 6,016 & 204 &, 000 \\
& female & 100 & 21,91 & 3,39 & & & \\
\hline
\end{tabular}

\section{Assessing the relevance of current educational level}

My main research goal was to judge whether or not current educational level is a more relevant concept than the notion of parental education that has been used in (multi)media research so far. Therefore, General Linear Models (GLM) were constructed in which the main effects of gender, current educational level, educational level of the mother and educational level of the father as well as the interaction effect of gender and current educational level were included. The interaction effect of gender and current educational level is discussed in the next paragraph. Here, the emphasis is on the comparison of the predictive power of the (significant) main effects using the squared Eta's of the independent variables. The results (see table 8) reveal that, even when controlled for gender, the educational level of the mother and the educational level of the father; adolescents' current educational level remains a significant factor. The educational level of the father, on the other hand, was significant only in the computer anxiety model and the educational level of the mother in none. The data thus suggest that when adolescents' scores on computer applications and computer attitudes are controlled for gender and current educational level, the influence of parental education becomes insignificant. In assessing these results, however, one should be aware of the fact that although current educational level was a significant factor in each model, the explicative power $\left(\mathrm{Eta}^{2}\right)$ of gender in these models was far more important than the one of current educational level.

\section{The interaction effect of gender and education}

The final step in my analysis was to test whether or not a significant interaction effect of gender and educational level exists with respect to computer use and computer attitudes with secondary school students. Therefore, an interaction effect between gender and current educational 
Table 8. GLM for computer applications/attitudes * gender/current educational levell educational level of the fatherleducational level of the mother.

\begin{tabular}{|c|c|c|c|c|c|}
\hline Dependent & Df. & $F$ & Sig. & $\mathrm{Eta}^{2}$ & $\mathrm{R}^{2}$ \\
\hline $\begin{array}{l}\text { Frequency of using video or computer games } \\
\text { Educational level }{ }^{*} \text { gender } \\
\text { Educational level mother } \\
\text { Educational level father } \\
\text { Current educational level } \\
\text { Gender }\end{array}$ & $\begin{array}{l}2 \\
3 \\
3 \\
2 \\
1\end{array}$ & $\begin{array}{r}10,257 \\
, 392 \\
1,300 \\
3,729 \\
59,058\end{array}$ & $\begin{array}{l}, 000 \\
, 000 \\
, 759 \\
, 277 \\
, 026 \\
, 000\end{array}$ & $\begin{array}{l}, 120 \\
, 008 \\
, 025 \\
, 047 \\
, 282\end{array}$ & .479 \\
\hline $\begin{array}{l}\text { Preference for using video or computer games } \\
\text { Educational level * gender } \\
\text { Educational level mother } \\
\text { Educational level father } \\
\text { Current educational level } \\
\text { Gender }\end{array}$ & $\begin{array}{l}2 \\
3 \\
3 \\
2 \\
1\end{array}$ & $\begin{array}{r}7,560 \\
, 590 \\
1,084 \\
1,951 \\
52,919\end{array}$ & $\begin{array}{l}, 000 \\
, 001 \\
, 622 \\
, 358 \\
, 046 \\
, 000\end{array}$ & $\begin{array}{l}, 092 \\
, 012 \\
, 021 \\
, 025 \\
, 296\end{array}$ & .427 \\
\hline $\begin{array}{l}\text { Frequency of surfing the Internet } \\
\text { Educational level * gender } \\
\text { Educational level mother } \\
\text { Educational level father } \\
\text { Current educational level } \\
\text { Gender }\end{array}$ & $\begin{array}{l}2 \\
3 \\
3 \\
2 \\
1\end{array}$ & $\begin{array}{r}, 511 \\
, 350 \\
2,277 \\
3,161 \\
, 117\end{array}$ & $\begin{array}{l}, 025 \\
, 601 \\
, 789 \\
, 082 \\
, 045 \\
, 733\end{array}$ & $\begin{array}{l}, 007 \\
, 007 \\
, 044 \\
, 041 \\
, 001\end{array}$ &, 133 \\
\hline $\begin{array}{l}\text { Preference for surfing the Internet } \\
\text { Educational level * gender } \\
\text { Educational level mother } \\
\text { Educational level father } \\
\text { Current educational level } \\
\text { Gender }\end{array}$ & $\begin{array}{l}2 \\
3 \\
3 \\
2 \\
1\end{array}$ & $\begin{array}{r}, 357 \\
, 179 \\
, 867 \\
, 313 \\
2,480\end{array}$ & $\begin{array}{l}, 726 \\
, 700 \\
, 910 \\
460 \\
, 732 \\
, 118\end{array}$ & $\begin{array}{l}, 005 \\
, 004 \\
, 018 \\
, 004 \\
, 017\end{array}$ &, 052 \\
\hline $\begin{array}{l}\text { Frequency for using e-mail } \\
\text { Educational level * gender } \\
\text { Educational level mother } \\
\text { Educational level father } \\
\text { Current educational level } \\
\text { Gender }\end{array}$ & $\begin{array}{l}2 \\
3 \\
3 \\
2 \\
1\end{array}$ & $\begin{array}{r}, 391 \\
, 164 \\
1,803 \\
7,008 \\
, 044\end{array}$ & $\begin{array}{l}, 002 \\
, 677 \\
, 921 \\
, 149 \\
, 001 \\
, 835\end{array}$ & $\begin{array}{l}, 005 \\
, 003 \\
, 035 \\
, 087 \\
, 000\end{array}$ &, 177 \\
\hline $\begin{array}{l}\text { Preference for using e-mail } \\
\text { Educational level } * \text { gender } \\
\text { Educational level mother } \\
\text { Educational level father } \\
\text { Current educational level } \\
\text { Gender }\end{array}$ & $\begin{array}{l}2 \\
3 \\
3 \\
2 \\
1\end{array}$ & $\begin{array}{r}, 088 \\
, 580 \\
1,185 \\
4,699 \\
, 672\end{array}$ & $\begin{array}{l}, 029 \\
, 916 \\
, 629 \\
, 317 \\
, 011 \\
, 414\end{array}$ & $\begin{array}{l}, 001 \\
012 \\
, 023 \\
, 060 \\
, 005\end{array}$ &, 131 \\
\hline $\begin{array}{l}\text { Frequency for using chat } \\
\text { Educational level }{ }^{*} \text { gender } \\
\text { Educational level mother } \\
\text { Educational level father } \\
\text { Current educational level } \\
\text { Gender }\end{array}$ & $\begin{array}{l}2 \\
3 \\
3 \\
2 \\
1\end{array}$ & $\begin{array}{r}1,952 \\
, 442 \\
1,548 \\
3,367 \\
, 192\end{array}$ & $\begin{array}{l}, 033 \\
146 \\
, 723 \\
, 205 \\
, 037 \\
, 662\end{array}$ & $\begin{array}{l}, 026 \\
, 009 \\
, 030 \\
, 043 \\
, 001\end{array}$ &, 128 \\
\hline
\end{tabular}


Table 8. Continued

\begin{tabular}{|c|c|c|c|c|c|}
\hline Dependent & Df. & $\mathrm{F}$ & Sig. & $\mathrm{Eta}^{2}$ & $\mathrm{R}^{2}$ \\
\hline Preference for using chat & & & ,211 & & ,091 \\
\hline Educational level $*$ gender & 2 & 2,650 &, 074 &, 035 & \\
\hline Educational level mother & 3 & 1,366 & ,256 &, 027 & \\
\hline Educational level father & 3 &, 633 &, 595 &, 013 & \\
\hline Current educational level & 2 & 2,001 & 139 &, 027 & \\
\hline Gender & 1 & 2,636 & , 107 &, 018 & \\
\hline Frequency for using the computer functionally & & & ,026 & & ,134 \\
\hline Educational level * gender & 2 & ,746 & 476 &, 010 & \\
\hline Educational level mother & 3 &, 319 & 436 & 018 & \\
\hline Educational level father & 3 & 338 & ,798 &, 007 & \\
\hline Current educational level & 2 & 5,261 &, 006 &, 067 & \\
\hline Gender & 1 & 5,708 &, 018 &, 037 & \\
\hline Preference for using the computer functionally & & &, 000 & & ,321 \\
\hline Educational level * gender & 2 & 2,961 & 055 & 038 & \\
\hline Educational level mother & 3 & 318 & 812 & 006 & \\
\hline Educational level father & 3 & 1,967 & 120 & 039 & \\
\hline Current educational level & 2 & ,768 & 466 &, 010 & \\
\hline Gender & 1 & 36,634 &, 000 & ,198 & \\
\hline Computer confidence & & &, 000 & & ,366 \\
\hline Educational level $*$ gender & 2 & 5,966 &, 003 &, 088 & \\
\hline Educational level mother & 3 & ,948 &, 420 &, 023 & \\
\hline Educational level father & 3 & 1,562 & ,202 &, 037 & \\
\hline Current educational level & 2 & 3,180 &, 045 &, 049 & \\
\hline Gender & 1 & 22,666 &, 000 &, 156 & \\
\hline Computer liking & & &, 000 & & 315 \\
\hline Educational level $*$ gender & 2 & 7,535 &, 001 &, 097 & \\
\hline Educational level mother & 3 &, 702 &, 553 &, 015 & \\
\hline Educational level father & 3 & 1,650 &, 181 &, 034 & \\
\hline Current educational level & 2 & 3,852 &, 024 &, 052 & \\
\hline Gender & 1 & 17,097 &, 000 &, 109 & \\
\hline Computer anxiety & & &, 000 & & ,323 \\
\hline Educational level * gender & 2 & 3,462 & 034 &, 048 & \\
\hline Educational level mother & 3 & 2,441 &, 067 &, 050 & \\
\hline Educational level father & 3 & 5,256 &, 002 &, 103 & \\
\hline Current educational level & 2 & 6,513 &, 002 &, 086 & \\
\hline Gender & 1 & 15,728 &, 000 &, 102 & \\
\hline Computer usefulness & & &, 000 & & ,237 \\
\hline Educational level * gender & 2 & ,348 & ,706 &, 005 & \\
\hline Educational level mother & 3 & 1,521 & ,212 &, 033 & \\
\hline Educational level father & 3 &, 032 & ,992 &, 001 & \\
\hline Current educational level & 2 & 2,106 & 126 & 033 & \\
\hline Gender & 1 & 24,673 &, 000 &, 156 & \\
\hline
\end{tabular}


level was added to the general linear models (GLM) that were constructed. As noted before, the models also tested the main effects of gender, current educational level and the educational level of the father and the mother (table 8). The existence of such an interaction effect would indicate that the pattern of the relationship between educational level and the dependent variable is different in both sub-groups. To be able to identify and judge these interacting relationships in more detail, new ANOVAs with post-hoc Tuckey's were run separately for boys and girls every time a significant interaction effect was found in the GLM.

Computer applications. A significant interaction effect with respect to computer applications was found only for computer game playing and preference. The GLM plot (figure 1) for computer game playing shows a negative linear relationship for girls and some curvilinearity with a maximum in middle education for boys. As such the GLM indicates for girls that, as educational level increases, computer game playing decreases. In respect to boys, computer game playing peaks in the middle education group. A new ANOVA, separately run for boys and for girls, indicates that these assumptions are correct and that between group differences for educational level with the dependent variable indeed exist. The posthoc Tukey test for boys showed no difference between the high and low education groups and between low and middle groups. The difference between high and middle education, however, proved to be significant. These results give evidence for the assumption of curvilinearity made earlier. It appears that middle education boys play computer games most. Boys in high and low education play less but do not differ significantly from one another. For girls, the post-hoc Tukey test revealed significant differences between the low and high as well as the low and middle education groups. Here, the assumption of a negative linear relationship made earlier was also confirmed. The latter means that computer game playing in girls is lowest in high education, higher in middle education and highest in low education.

On face value, similar conclusions can be drawn from the GLM plot for computer game preference (figure 2). The new ANOVA for boys, however, indicates that the relationship between educational level and computer game preference that was found, could not be maintained. In fact, for boys no relationship between educational level and the dependent variable could be found. In the female group, however, the same negative linear relationship that was found for computer game playing was replicated. One can conclude that for girls higher education correlates with lower computer game preference. The post-hoc Tukey test indicated that significant between group differences could indeed be found between the scores of the low and the middle education students. 
Computer game playing

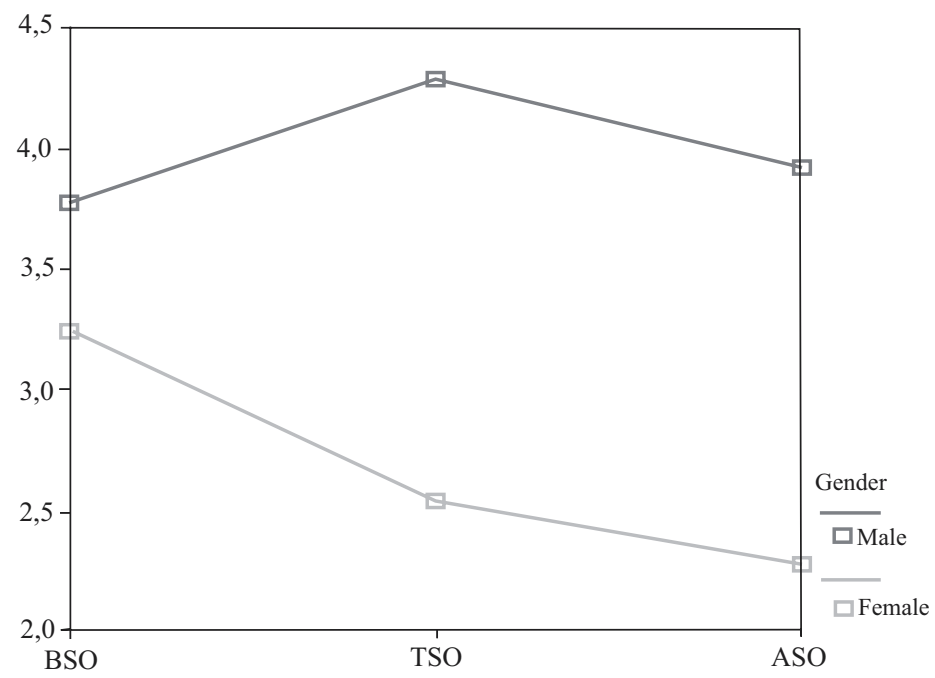

Educational level

Figure 1. GLM plot for computer game playing * educational level * gender.

Computer game liking

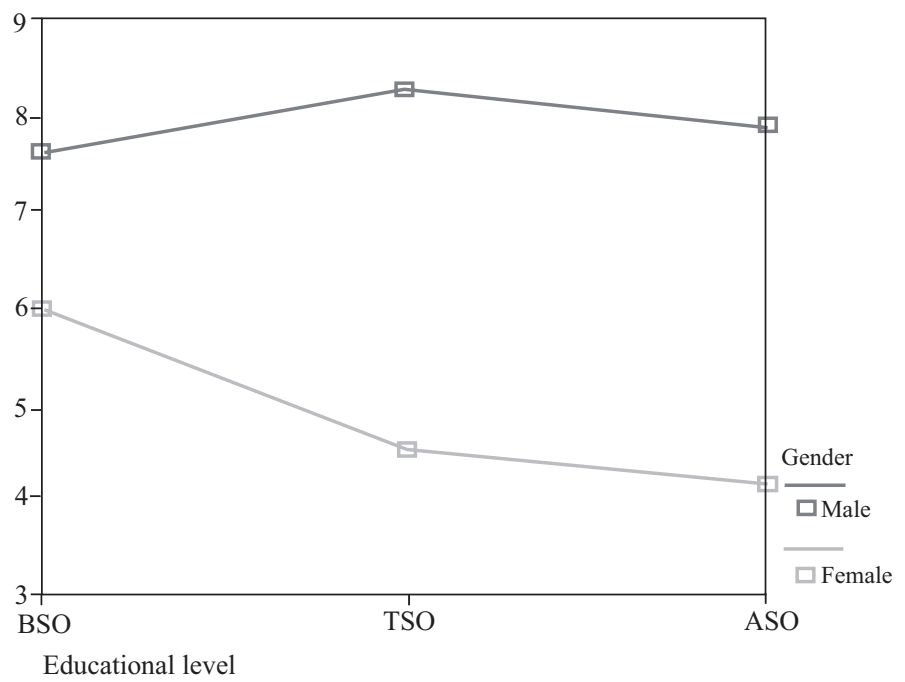

Figure 2. GLM plot for computer game liking * educational level * gender. 
Computer confidence

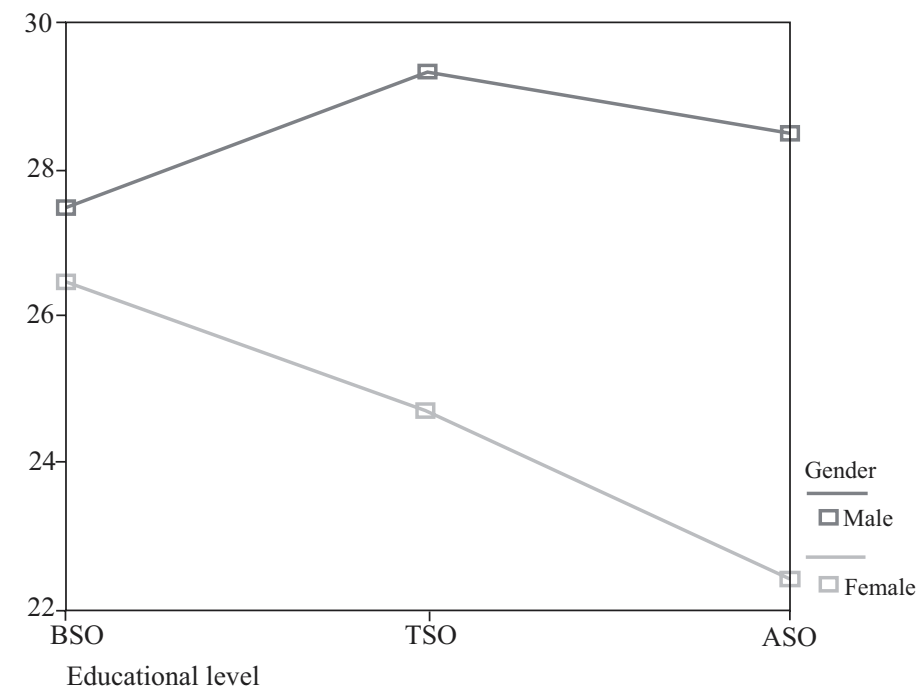

Figure 3. GLM plot for computer confidence * educational level * gender.

Computer attitudes. A GLM was also run for each of the four factors of the computer attitude scale of Loyd and Loyd (1985). The only model that could not produce a significant interaction effect of gender and educational level with the dependent variable was the one for computer usefulness. The GLM plot for computer confidence suggests that the pattern of a curvilinear relationship for boys and a negative linear relationship for girls is reproduced. The ANOVA with post-hoc Tukey test for boys, however, does not provide support for this assumption. In fact, both the ANOVA and Tukey test results suggest that for boys educational level and computer confidence are in no way related. Conversely, in respect to the female group, the negative linear relationship that was assumed remains significant after both the ANOVA and Tukey test. In fact, the latter reveals that the between group differences found through comparison of the low and high and middle and high education groups are significant. Computer confidence is thus highest in girls in low and middle education. Both groups do not differ from one another but together they differ significantly from the high education girls. The latter group seems to have the least computer confidence.

The GLM for the computer liking attitudes was also able to generate the expected interaction effect. The results produced by this model are similar to the ones found for computer confidence. In this model, though, the curvilinear relationship for boys between the dependent and 
Computer liking

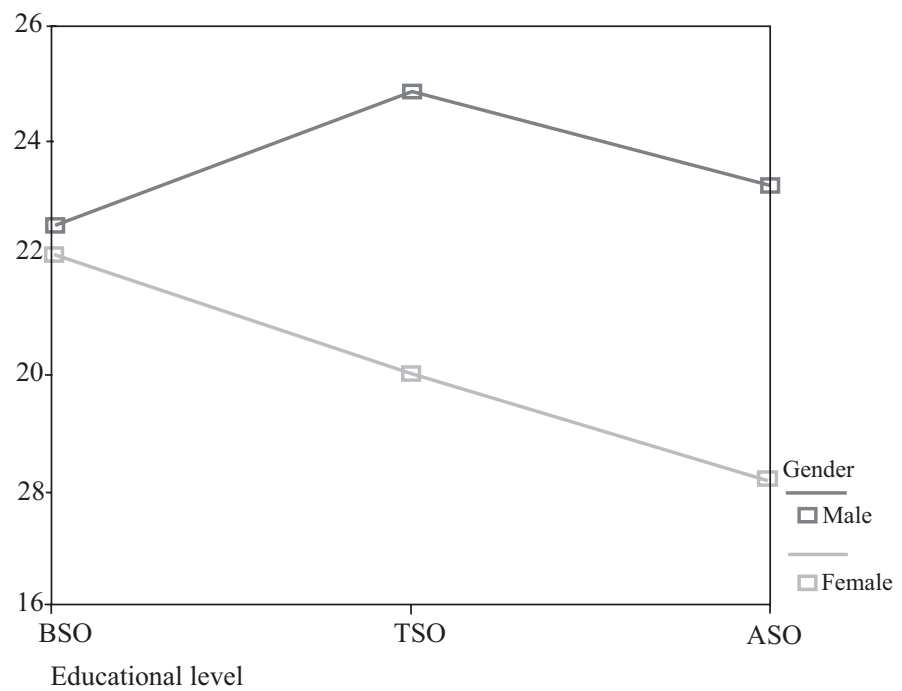

Figure 4. GLM plot for computer liking * educational level * gender.

the independent variables holds after both ANOVA and Tukey test control. The ANOVA results supported the assumption that significant between group differences were to be found. By means of a post-hoc Tukey test it was found that the low and the middle education group differ significantly. The ANOVA for girls also suggested some significant between group differences. The post-hoc Tukey test showed every between group comparison to result in significant differences. In fact, the low education group scored higher than both the middle and high education groups and the middle education students scored higher on the computer liking scale than the high education respondents. The latter group produced the lowest mean score on this particular scale. Consequently, the assumption of a negative linear relationship was again supported by the fact that as the level of education increases, computer liking decreases.

The last computer attitude for which a significant interaction effect of gender and educational level could be noted was computer anxiety. Since this was the only scale that measured a negative attitude towards computers it should not come as a surprise that the relationships found were similar but reversed in comparison to the ones that had been noted on the other two attitude scales. The ANOVA and Tukey test again proved the curvilinear relationship for boys to persist with significant between differences found between the low and middle and between the middle and high education groups. Both the low and high education 


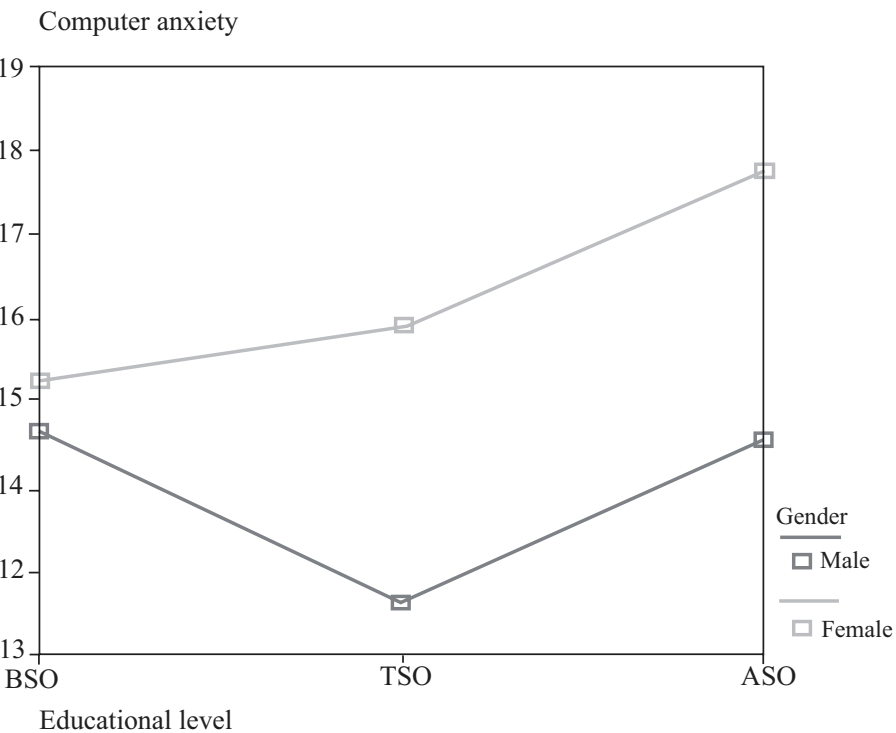

Figure 5. GLM plot for computer anxiety * educational level * gender.

students score lower than the middle group but low and high do not differ from one another. For girls a positive linear relationship between the dependent and independent variables was found. The ANOVA suggested that significant between group differences were to be found. The Tukey test indicated that the low and middle education groups scored significantly lower than the high education students.

\section{Discussion}

The starting point of this study was the postulation by Rosengren and Windahl (1989) that when children become adolescents, class of destination rather than class of origin becomes the better indicator of social class. This statement led me to consider whether or not current educational level should be included in the measurement of social class in adolescents and to what extent this is related to parental education. The problem with the latter concept is that the educational level of the parents is not always a good predictor of the social status that will be acquired by their children. In previous research the transition of children to a social class different to that of their parents has been referred to as 'social mobility' (Roe, 1994). In my data, the presence of a significant amount of droppers and climbers has led me to the assumption that the educational level of the parents is a good, but not a perfect predictor of current educational level. 
First, the data presented in this article suggest that current educational level is indeed a meaningful concept in multimedia research. Additionally, the research goal of assessing the relevance of current educational level as a measure of class of destination within the general concept of social class was met. It seems that when current educational level is controlled for, the educational level of the father and of the mother become insignificant, whereas current educational level and the interaction effect between gender and educational level remain significant. One possible explanation could be that the direct relationship between parental education and computer use is at least to some extent sparse and as such mediated by current educational level. In other words, the relationship between parental education and computer use could then be explained by a third factor. The data supports the assumption that this underlying variable could be current educational level. It should be added, however, that in the one model where the educational level of the father did emerge as significant, the eta ${ }^{2}$ of the latter variable was higher than the one for current educational level. This means that in the case of computer anxiety, the educational level of the father is a better predictor of the dependent variable than current educational level.

Nevertheless, it seems that the models in which current educational level is included predict the outcome of computer use and attitudes very well. The explained variances of these models, for example, varied from: .479 with respect to video and computer game playing, .366 for computer confidence, .321 for preference for using the computer functionally, .315 for computer liking and .323 for computer anxiety.

I therefore believe that there is considerable data suggesting that future research on the relationship between social class and multimedia use within adolescents should take current educational level into account. One possible problem could be, however, that not all countries necessarily make the distinction between different levels of secondary education that clearly. Even in those countries, however, it may be advisable to search for different methods of operationalizing some concept of current educational level. One could focus, for example, on the average expected academic achievement of different types of study or even different schools. Another possibility has been suggested by Roe (1989) in his research on children's VCR use. Roe tested the relationship between social class and VCR use by using a model in which socio economic status of the parents indirectly influenced the dependent variable trough school achievement and academic self concept. This model not only shows that the relationship between social class and media use can be measured in many different ways (school achievement, academic self concept). It also suggests that when no direct relationship between parental SES can be found, the latter concept can still be meaningful in terms 
of an indirect influence. In later years Roe $(1992,1998)$ also applied his model of parental socio-economic status to the relationship with school achievement and academic self concept on children's musical preferences and computer game playing. Highly relevant for this research, however, is the fact that especially academic self concept provides a possible explanation for the relationship between current educational level and class of destination that has been found on the basis of my data.

There are probably many ways in which educational or even professional aspirations can be measured and investigated. This study focused specifically on current educational level and its comparison to the educational level of the parents. One possibility for future research could be to investigate and compare current educational level with other operationalizations such as the ones that were suggested in the previous paragraph. Yet another possibility for future research is to focus on the evolution in the relative importance of parental education versus current educational level throughout the different stages of adolescence. When is it advisable to focus on parental education and when should the shift be made to current educational level? In other words, at what age does current educational level become more important than parental education? In the present study all respondents were in the third or fourth grade of secondary school but what would have happened if we had focused on fifth and sixth or even first and second graders? Clearly, a number of research questions still remain in this particular domain. However, when conducting such research the interacting force of gender should be borne in mind because, as Rosengren and Windahl (1989) and Roe $(1998,2000)$ have pointed out, the relationship between social class and media use is differentially structured along the lines of gender.

\section{Conclusions}

The data presented in this paper allow me to draw several conclusions. My first object of attention was the question whether or not current educational level is at all a meaningful concept in multimedia research. Previous research in attitudes towards and use of multimedia in adolescents had never focused on the relationship with current educational level. In this study, the existence of significant between group differences for the high, middle and low educational groups give considerable support to the assumption that a significant relationship between current educational level and computer use/attitudes indeed exists.

In general, my models suggest that a positive linear relationship between current educational level and computer use exists whereby high education students used these computer applications the most followed by middle education students and the low education group. It should be 
added, however, that the difference between the latter two groups were only found to be significant in the e-mail frequency model. In respect to Internet and chat frequency, low and middle education students seem to constitute one cluster. Yet another pattern of between group differences has been noted in the model of functional computer use. Here the high and middle education groups constitute one cluster scoring higher than the low education group.

In spite of these differences in between group patterns a general conclusion can still be drawn. First of all, high education students score significantly higher than the low education students in every model. The second conclusion is more complex and concerns the position of the middle group. It seems that when computer use is measured in terms of entertainment (Internet, chat) middle education students are similar to their low educated peers. Whenever the computer is used functionally (doing homework), however, they behave more like high education students. As for computer attitudes, the same conclusions can be drawn from these data. When computer use is defined in terms of amusement (Computer liking attitude) middle education students do not differ from low education. When computer use is measured functionality (Computer usefulness attitude) they join up with their high education peers. As for the differences between high and low education, the results indicate that computer attitudes are more positive in high than in low education. In fact, high level students score higher on both the computer liking and computer usefulness scales.

The latter distinction between functional computer use and computer use in terms of entertainment is new. Future researchers should keep in mind that the relationship between educational level and computer use is at least in some way dependent of the way in which computer use itself is measured.

\section{References}

Bourdieu, P. and Patterson, J. C. (Eds.). (1977). Reproduction in education, society and culture. Londen: Sage.

Brown, D., Childers, J., and Walsh, K. (1990). The influence of new media and family structure on young adolescents' television and radio use. Communication research, $17(1), 65-82$.

Busch, T. (1995). Gender differences in self-efficacy and attitudes towards computers. Journal of Educational Computing research, 12(2), 147-158.

Entwisle, D. R. and Astone, N. M. (1994). Some practical guidelines for measuring youth's race/ethnicity and socioeconomic status. Child Development, 65, 15211540 .

Field, A. (Ed.). (2000). Discovering statistics using SPSS for Windows. London: Sage.

Ho, S. M. Y. and Lee, T. M. C. (2001). Computer usage and its relationship with adolescent lifestyle in Hong Kong. Journal of Adolescent Health, 29(4), 258-266. 
Johnssons-Smaragdi, U., d'Haenens, L., Krotz, F., and Hasebrink, U. (1998). Patterns of old and new media use among young people in Flanders, Germany and Sweden. European Journal of Communication, 13(4), 479-492.

Kluever, R. C., Lam, T. C. M., Hoffman, E. R., Green, K. E., and Swearing, D. L. (1994). The computer attitude scale: Assessing changes in teachers' attitudes toward computers. Journal of Educational Computing Research, 11(3), 251-161.

Loyd, B. H. and Gressard, C. (1984). The effects of sex, gender and computer experience on computer attitudes. Association for Educational Data Systems Journal, 18, $67-77$.

Loyd, B. H. and Loyd, D. E. (1985). The reliability and factorial validity of computer attitude scales. Educational and Psychological Measurement, 45, 903-908.

Muijs, D. (Ed.). (1997). Self, school and media: A longitudinal study of media use, self concept, school achievement and peer relations among primary school children. Leuven: K. U. Leuven, Department of Communication Science.

Nash, J. B. and Moroz, P. A. (1997). An examination of the factor structures of the computer attitude scale. Journal of Educational Computing Research, 17(4), $341-356$.

Pasquier, D., Buzzi, C., d'Haenens, L., and Sjöberg, U. (1998). Family lifestyles and media use patterns: An analysis of domestic media among Flemish, French, Italian and Swedish children and teenagers. European Journal of Communication, 13(4), $503-520$.

Roe, K. (1998). Boys will be boys and girls will be girls: Changes in children's media use. Communications, 23(1), 5-25.

Roe, K. (1998). Children and computer games: A profile of the heavy user. European Journal of Communication, 13(2), 181-200.

Roe, K. (1992). Different destinies - different melodies: School achievement, anticipated status and adolescents' tastes in music. European Journal of Communication, $7(3), 335-357$.

Roe, K. (1994). Media use and social mobility. In K. E. Rosengren (Ed.), Media effects and beyond. London: Routledge.

Roe, K. (1989). School achievement, self-esteem, and adolescents' video use. In M. R. Levy (Ed.), The VCD age: Home video and mass communication. London: Sage.

Roe, K. (2000). Socio-economic status and children's television use. Communications, 25(1), 3-18.

Rosengren, K. E. and S. Windahl (Ed.). (1989). Media matter: TV use in childhood and adolescence. $\mathrm{NJ}$ : Ablex.

Stinissen, J. (Ed.). (1987). De overgang van secudair naar hoger onderwijs. Leuven: Acco.

Subrahmanyam K., Kraut R. E., Greenfield P. M., and Gross, E. F. (2000). The impact of home computer use on children's activities and development. Future of Children, 10(2).

Van Rompaey, V. (2002). Media on/Family off? An integrated quantitative and qualitative investigation into the implications of Information and Communication Technologies (ICT) for family life. Leuven: K. U. Leuven, Department of Communication Science. 